\title{
NOVEDADES EPIGRÁFICAS EN EL MEDIO EBRO (LA RIOJA)
}

\author{
URBANO ESPINOSA \\ Ma JOSÉ CASTILLO PASCUAL \\ Universidad de La Rioja
}

\begin{abstract}
En la primera parte de este trabajo se dan a conocer siete nuevas inscripciones en piedra de territorio riojano, conteniendo información novedosa principalmente sobre el ejército y las comunicaciones antiguas. En la segunda parte se recogen las inscripciones de nueve vasos cerámicos, hallados en Vareia (Varea, Logroño) y producidos en Calagurris Iulia por el officinator de esa ciudad G. Valerius Verdullus; son un magnífico exponente de la romanización del Ebro al final del período julio-claudio.

The first part of this paper deals with seven new inscriptions over stone found in the territory of La Rioja, which give new information mainly about the army and the old communications. The second part deals with the inscriptions over nine ceramic vases found in Vareia (Varea, Logroño) and made in Calagurris Iulia by G. Valerius, the officinator of that town. They are a magnificent proof of the romanization of the Ebro at the end of the period JuliusClaudius.
\end{abstract}

Damos a conocer aquí varios hallazgos epigráficos habidos en el área riojana del medio Ebro durante los últimos años. Son inscripciones inéditas, o insuficientemente conocidas, producto de hallazgos casuales y, por tanto, conteniendo textos de carácter muy diferente entre sí (fig. 1). Añadimos al final una recopilación de inscripciones menores sobre cerámica, halladas en el ager Vareiensis y moldeadas todas ellas por el calagurritano G. Valerius Verdullus; su singularidad les permite ocupar un lugar destacado dentro del instrumentum domesticum. El ámbito territorial de unos y otros hallazgos pertenecía en la división administrativa altoimperial a la parte occidental del conventus Caesaraugustanus de la provincia Hispania Citerior.

Seis de las siete inscripciones en piedra aparecen en luga- res situados a lo largo de la calzada del Ebro. Registramos dos miliarios, augusteo uno en el municipio Calagurris Iulia Nassica (Calahorra) y de Claudio el otro en Tritium Magallum, tres inscripciones funerarias en Vareia (Varea, Logroño), de las cuales una parece ser cristiana, y finalmente dos aras votivas en Libia (Herramélluri) y Montemediano (Nieva de Cameros). Las seis primeras inscripciones pertenecen a unidades urbanas bien definidas, mientras que la última aparece en la zona montañosa de Camero Nuevo, poblada en época romana por comunidades pastoriles asentadas en habitat disperso, donde existió una officina lapidaria y donde conocemos ya un interesante grupo de una veintena de inscripciones (ESPINOSA 1986 y 1989). 


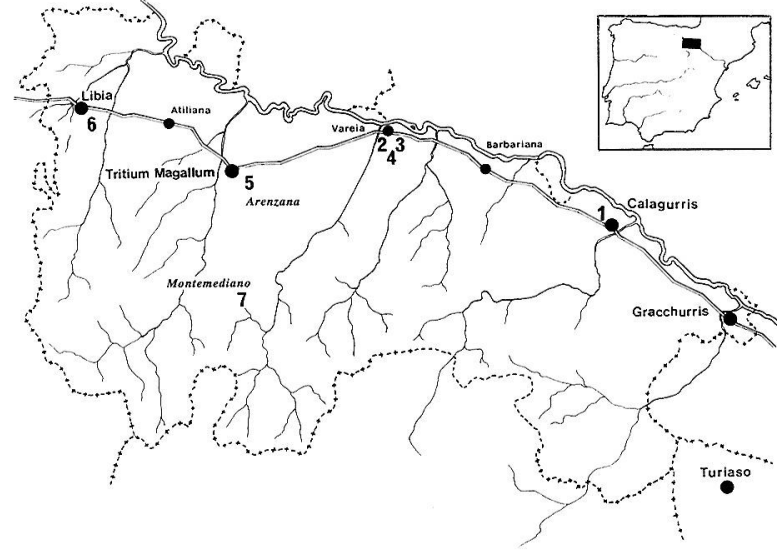

Fig. 1.- Novedades de epigrafía en piedra de territorio riojano

\section{NOVEDADES DE EPIGRAFÍA EN PIEDRA}

\section{Calagurris (Calahorra).- Miliario.}

Tambor con arenisca de $25 \mathrm{~cm}$. de altura y $50 \mathrm{~cm}$. de diámetro. Completo, salvo desgaste fuerte en aristas. Corresponde a la parte media de un miliario formado por superposición de piezas similares. Conserva las 3 líneas centrales del texto, líneas cuyos límites superiores e inferior coinciden con los del cilindro. Letras de ductus regular y $6 \mathrm{~cm}$. de altura, salvo las dos últimas $\mathrm{T}$ de lín. 4 con $7,5 \mathrm{~cm}$. Interpunción de puntos triangulares.

Noticia primera del hallazgo en El Correo Español-El Pueblo Vasco (Edic. Rioja), 3.2.1989, p. 6; el fragmento de miliario apareció en febrero de 1989 en las inmediaciones del Hospital Viejo de Calahorra, no lejos de su emplazamiento originario, pues por ahí la vía del Ebro, nada más cruzar el puente sobre el río Cidacos, penetraba en el núcleo urbano de Calagurris viniendo de Caesaraugusta (sobre el puente, ESPINOSA 1984 126). Por tanto, su indicativo de millas señalaría exactamente el emplazamiento de Calagurris en la calzada procedente de la capital del conventus. La pieza se guarda en el Museo Municipal de Calahorra; autopsia, calco y fotografía en septiembre de 1989 (colaboración y fotos de J. Martínez Clemente). Lectura (fig. 2):

\section{[Imperator $\cdot$ Caes(ar)]}

[Divi-f(ilius).Augustus]

co(n)s(ul) XI·imp(erator) XIII

tribunic(ia).potest(ate)

5 XV·Poftu[f(ex)]·Max(umus)

Muy deterioradas las letras de líns. 3 y 5 , pero son reco-

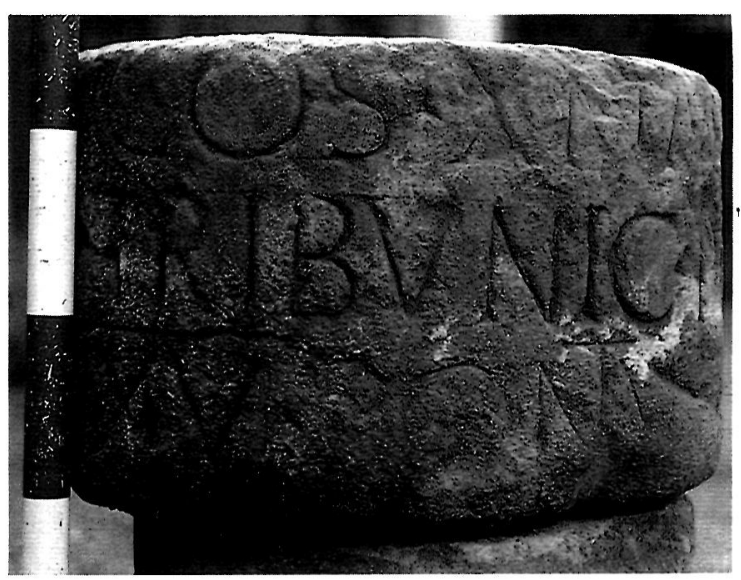

Fig. 2.- Calagurris: miliario augusteo (foto J. Martínez).

nocibles. Ligadura NT en lín. 5 y el numeral XV aparece reesculpido en campo rebajado. Reconstruimos la onomástica inicial según miliarios coetáneos aparecidos en la región del Ebro. De acuerdo con estos mismos testimonios, tal vez en una 6. lín. podría mencionarse la legio $V I$, pues es habitual que en los miliarios augusteos de la región se recuerden las unidades militares encargadas de reparar o construir la red viaria tras las Guerras Cántabras. Uno del 9 a.C., procedente tal vez de Castiliscar (Navarra), menciona la leg. IIII Macedonica (CASTILLO et alii 1981, n. ${ }^{\circ}$ ); otro de igual fecha en Egea de los Caballeros (Zaragoza) donde aparece la leg. X Gemina (BELTRÁN, 1969/70, 99-100) y otro del año 5 a.C. de Castiliscar con recuerdo de la leg. VI (CASTILLO et alii, 1981, $\mathrm{n}^{\circ}$ 2); precisamente en Calahorra hubo un destacamento de la citada legión (ESPINOSA 1986, n. ${ }^{\circ}$ 6). Sobre unidades militares y calzadas, LE ROUX 1982, $84 \mathrm{~s}$.

El texto del miliario calagurritano concluiría con el número de millas, seguramente contadas a partir de Caesaraugusta (vid. n. ${ }^{\circ}$ 5). El ejemplar es del año 9 a.C., por tanto coetáneo, junto a los citados de Egea y Castiliscar, también a los cuatro fragmentarios de Fraga (Lérida) (CIL II 4920-4923) y a otro miliario de la vía costera entre Carthago Nova y el Pirineo (CIL II 4949 ss.; Itin. Ant. 392.2-393.1; ROLDÁN 1975, 42). El hallazgo de Calahorra contribuye a conocer mejor el programa augusteo de construcción de calzadas en el conventus Caesaraugustanus tras la pacificación del norte peninsular, así como la implicación del ejército en la supervisión y control de las obras. El miliario, colocado al pie del puente sobre el Cidacos data a la vez la construcción de éste y probablemente también la de otros puentes en la misma calzada. Por ejemplo, debe datarse en el 9 a.C., o en fecha muy próxima, el puente de Vareia sobre el Iregua (PASCUAL y ESPINOSA 1982, 70 ss., figs. 2-3). 


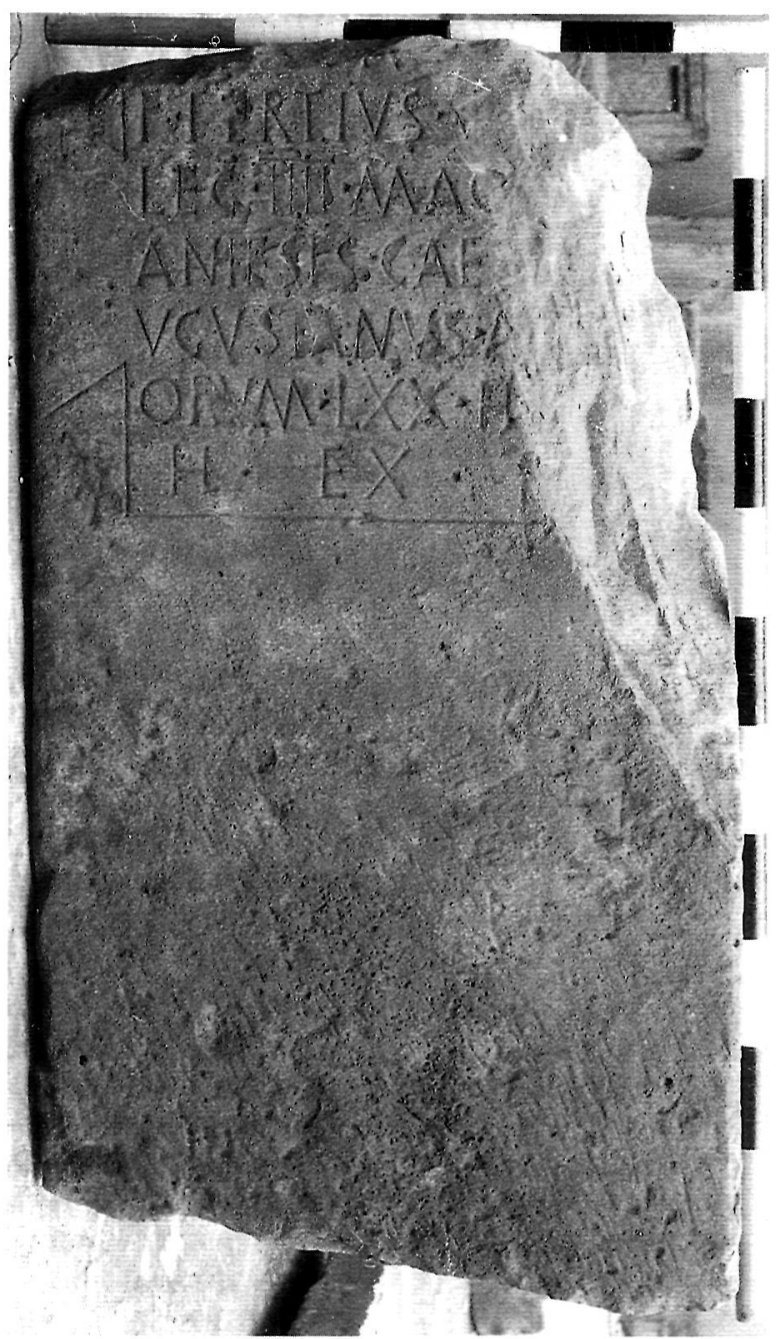

Fig. 3a.- Vareia: Estela funeraria del veterano Tertius (foto J.L. Martín).

\section{Vareia (Varea, Logroño).- Dedicación funeraria}

Estela en arenisca con pérdida de la cabecera y de la primera línea de texto: $(108) \times 63 \times 21 / 26 \mathrm{~cm}$. Falta el final de cada línea por fractura en el momento mismo del hallazgo. Campo epigráfico de $42 \times 50 \mathrm{~cm}$. en forma de tabula ansata, señalada con surco sencillo. Letras de $4,5 \mathrm{~cm}$.; puntos triangulares en todos los espacios interpalabras.

Apareció en noviembre de 1988 reutilizada en una tumba de lajas, seguramente medieval, del cementerio de Varea durante los trabajos de acondicionamiento del mismo. Seguramente apenas fue desplazada de su lugar originario, ya que el actual cementerio se ubica junto a la antigua calzada en

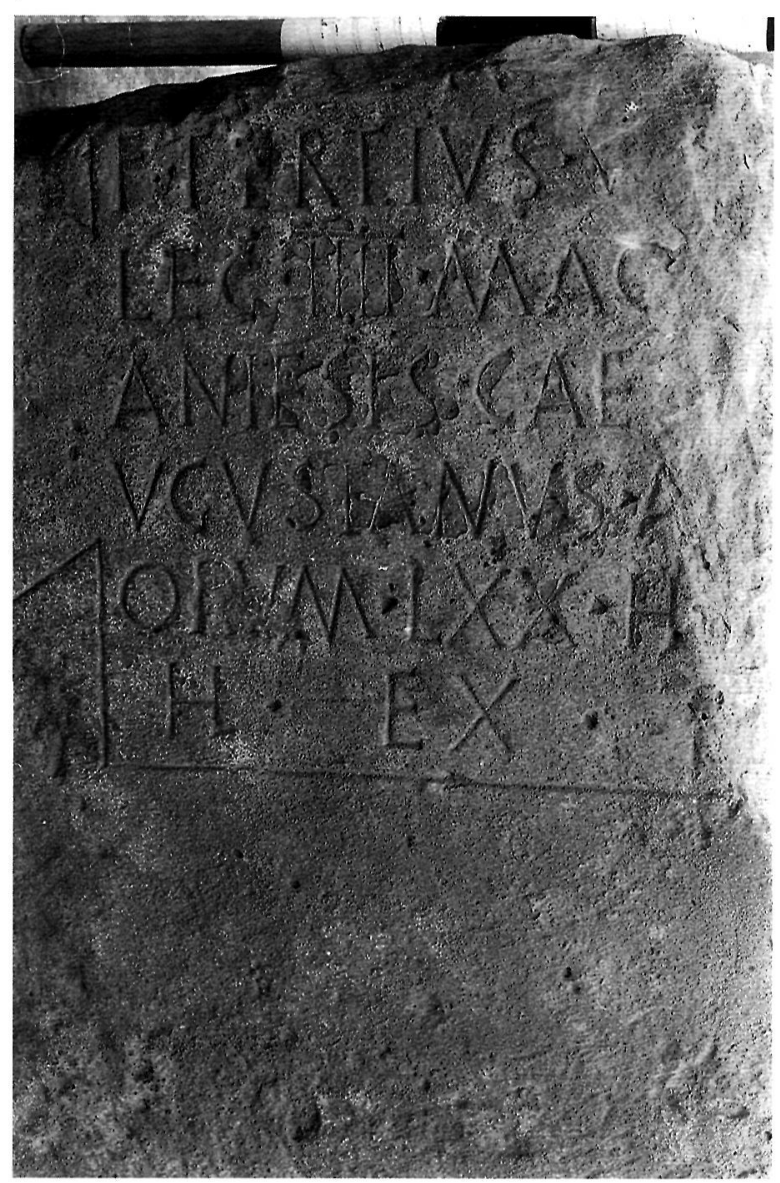

Fig. 3b.- Vareia: detalle de la estela de Tertius (foto J.L. Martín) .

su salida de Vareia hacia Calagurris. Se conserva en el Museo de La Rioja; inspección y foto en el punto de hallazgo en colaboración de J.L. Gómez Urdáñez. El texto dice (fig. 3 a y b):

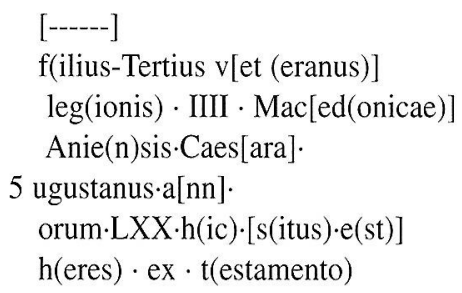

Casi al final de la primera línea perdida sólo se conserva el extremo inferior de dos trazos verticales; la línea contenía el praenomen y nomen del dedicado y concluía con la abreviatura del praenomen del padre. En annorum, probable ligadura AN. El final de las restantes líneas se restituye sin dificultad. Bibl.: ESPINOSA 1990, 11-13 y foto (de aquí, LE ROUX 1992, 250, n. ${ }^{\circ}$ ). 
La inscripción aporta un nuevo testimonio de la tribu Aniense en relación con Caesaraugusta (FATAS 1975, 135 ss.; WIEGELS 1985, 164) y de la leg. IIII Macedonica durante su estacionamiento en Hispania (CASTILLO 1981, 134-140 con bibl. anterior; LE ROUX, 1982, 109-120; id. 1992, 238 ss.). El destacamento vareyense de esta unidad ya era conocido por otra inscripción (ESPINOSA 1986, n. ${ }^{\circ}$ 20). Por lo demás, no es posible vincular al veterano Tertius, por el solo cognomen, con alguna de las familias conocidas de Caesaraugusta.

En cuanto a la cronología de la estela podemos determinar sus termini ante et post quem. Veamos el primero; Tertius tuvo que licenciarse en Vareia como más tarde cuando la partida de la legión IV a Germania hacia el 39-40 d.C., bien porque cumpliera en ese momento la edad de licenciarse (hacia los 45 años), bien porque le quedaran ya pocos años para el fin del servicio activo. De ahí que su septuagésimo y último año de vida no pueda datarse en ningún caso después del 65/70 d.C. Desde tal hipótesis, Tertius habría nacido en Caesaraugusta entre el 5 a.C. y el cambio de Era. Por el contrario, el terminus post quem se deduce como sigue: Tertius pudo haber nacido antes de que su padre fuera deducido a Caesaraugusta, pero no pudo alistarse en la legión IV hasta después de la fundación de la colonia, porque sólo entonces recuperó el padre el ius conubii y con él la legitimación de la prole y la transmisión a ella de la ciudadanía (tribu Aniense) y de la origo. Por tanto, Tertius se enrolaría lo más pronto hacia los 20 años de edad entre el 19 y el 13 a.C., las discutidas fechas de la fundación -de Caesaraugusta; desde tal supuesto, situaríamos la fecha más antigua posible de su fallecimiento a partir del 30/40 d.C.

Por ello creemos que su monumento funerario ha de datarse entre finales de Tiberio y de Nerón, si bien tales límites cronológicos deben ser tomados con flexibilidad, pues no ignoramos que, entre otros factores de inseguridad, la edad de Tertius aparece redondeada por lo menos en lustros.

En todo caso, Tertius pertenece a la segunda generación de cesaraugustanos y su inscripción prueba que la incorporación de los hijos al oficio militar del padre fue una de las vías seguidas por Augusto para provincializar el ejército hispano. Tras el licenciamiento, decidió Tertius no retornar a Caesaraugusta y permaneció en el mismo lugar del servicio. La explicación más verosímil es que los veteranos de la legión IV en Vareia debieron recibir junto con la honesta missio un lote de tierras; de ese modo el campamento vareyense se convirtió, tras el abandono de las tropas, en la Vareia de agricultores que conocemos por las fuentes escritas y arqueológicas. No cabe duda que la zona vareyense mantuvo estrechos lazos con Caesaraugusta; por la misma época que Tertius, la gens Iulia de esa ciudad casaba a Iulia Severina con M. Iulius Atticus, rico propietario en Velilla, a sólo $6 \mathrm{~km}$. de Vareia (ESPINOSA 1986, n. ${ }^{\circ}$ 17, p. 37-39); testimonios de los Iulii en Caesaraugusta, FATAS y MARTÍN, 1977, n. ${ }^{\circ} 69$ y 71 .

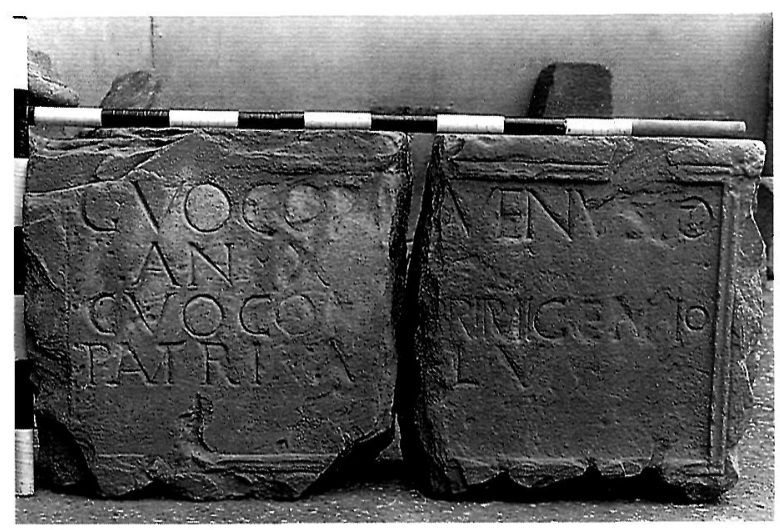

Fig. 4.- Vareia: losa funeraria de los Voconii (foto J.L. Martín

\section{Vareia (Varea, Logroño).- Losa funeraria.}

Dos fragmentos de bloque rectangular en arenisca con fractura vertical en la zona central que ha ocasionado la pérdida de letras en la banda media de la inscripción. Medida total: $55 \times 107 \times 28 \mathrm{~cm}$. Esquinas, aristas y superficie deterioradas. Campo epigráfico de $41,5 \times 97 \mathrm{~cm}$. enmarcado con moldura. Gran calidad paleográfica con letras capitales cuadradas de $7 \mathrm{~cm}$. en lín. 1, 6,5 en lín. 2 y $6 \mathrm{~cm}$. en líns. 3-4. La O de menor tamaño al final de líns. 1 y 3 . Puntos triangulares.

Inscripción funeraria notablemente deteriorada, aparecida en julio de 1988 formando parte de la cimentación de una vivienda de la Vareia bajoimperial (excavaciones de S. Andrés). Se conserva en el Museo de La Rioja; inspección en noviembre de 1990 y fotos de J.L. Martín. Lectura (fig. 4):

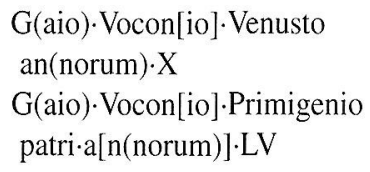

En lín. 1 son claras las huellas de la primera $\mathrm{N}$, de la $\mathrm{S}$ y de la T. En lín. 2 la superficie siguiente a X está más elevada que los surcos de esa letra, por lo que se descarta otro signo posterior. En lín. 3 una R tras PRI corregida por el lapicida a $\mathrm{M}$; el pequeño espacio entre $\mathrm{N}$ e I se debería al deterioro de la superficie en el momento de la talla. En lín. 4 nuevo error del cantero al unir A y T con trazo oblicuo; por analogía con lín. 2 hemos de suponer a[n(norum)]. Bibl.: ANDRÉS y TIRADO 1991, $10 \mathrm{~s}$.

Por el formulario y por la calidad paleográfica podría datarse la inscripción en el s. I d.C. El gentilicio Voconius se testimonia en numerosos puntos de la geografía peninsular, si bien a comienzos del Imperio y a lo largo del s. I los datos parecen limitarse casi exclusivamente a la línea Sagunto- 
Tarraco, ciudades donde los Voconii formaban parte de las respectivas élites locales (para Sagunto: BELTRÁN $1980 \mathrm{n}^{\circ}$ 47, 48, 63, 214; ALFÖLDY 1984, n. ${ }^{\circ} 217$; el rango y riqueza de algunos Voconii saguntinos, en Plinio, Epist. 2.13.4 y 10.4.2 (SYME 1960, 365 ss. = Roman Papers II, 1979, 480 ss.); para Tarraco: ALFÖLDY 1975, n. ${ }^{\circ} 356$; id. 1984, 230, n. ${ }^{\circ}$ 9). En general, sobre el nomen Voconius en Hispania, ABASCAL 1993 (prensa).

En los mismos cimientos de la vivienda donde apareció la inscripción había también aprovechados otros materiales del siglo I d.C., entre ellos una metopa de friso dórico, pertenecientes probablemente a un monumento funerario turriforme; fueron reutilizados juntos en el Bajo Imperio porque seguramente todos procedían del mismo monumento desmantelado (ESPINOSA 1995, prensa). Concluiríamos que la magnífica inscripción de los Voconii vareyenses formaba parte de una tumba de aparejo en forma de torre con friso dórico. Pues bien, hallamos sus paralelos más directos en el eje SaguntumTarraco-Barcino, precisamente allí donde testimoniamos los primeros Voconii de Hispania.

\section{Vareia (Varea, Logroño).- Losa funeraria cristiana.}

Ángulo superior derecho de una probable losa funeraria cristiana en piedra arenisca: (26) x (21) x 14,5 cm. Carece de molduras. Conserva la parte final de las dos primeras líneas y vestigios de una tercera. Letras de $7 \mathrm{~cm}$. bien marcadas con surco profundo. Apareció en enero de 1989 reutilizada en la vieja tapia del cementerio de Varea, de donde fue recuperada durante las obras de remodelación en el citado lugar (nuestro reconocimiento a J.L. Gómez Urdáñez, por cuya mediación pudo rescatarse la inscripción). Se conserva en el Museo de La Rioja. El texto es (fig. 5):

$$
\begin{gathered}
\text { [---]HRIS } \\
\text { [---]A } \\
{[---] A T R[.]}
\end{gathered}
$$

En lín. 1 «h» cursiva. Con toda probabilidad es A el primer resto de letra en lín. 2. En lín. 3 ligadura AT; sólo se conserva la mitad superior de R; le sigue un espacio vacío, insuficiente para una letra, y finalmente resta el extremo superior izquierdo de un trazo horizontal.

Difícil lectura; en lín. 1 hay que descartar un eventual cognomen griego basado en chrysos debido a la utilización de I en lugar de Y. El fragmentario texto cuadra bien con las fórmulas habituales de las inscripciones cristianas; en ese sentido, una hipótesis de lectura podría ser:

$$
\begin{aligned}
& \text { [--- in C]hris- } \\
& \text { [to --- k]al(endas) De- } \\
& \text { [cembres --- m/plâtr(i)? [.] }
\end{aligned}
$$

En lín. 1 constaría el nombre del/a difunto/a seguido de obiit, recessit, dormit o similar y en lín. 2 la fecha del fallecimiento. Existe noticia de otro fragmento de inscripción paleocristiana, hoy perdido, hallado en Varea y que recogía uno de esos verbos con la fórmula [- - - ] obiit [- - - ] (ESPINOSA 1986, p. 104).

\section{Arenzana de Arriba (territ. de Tritium Magallum).- Miliario.}

Fragmento de miliario en arenisca: $63 \mathrm{~cm}$. de diámetro y (72) de altura. Fue readaptado como contrapeso de prensa olearia en el Bajo Imperio, para lo cual se le practicó un canal de $14 / 16 \mathrm{~cm}$. de anchura en el diámetro inferior prolongado por los laterales; arriba se practicó un gran hueco ovoide de $29,7 / 30 \mathrm{~cm}$. de profundidad. Una de las dos acanaladuras laterales ha destruido la parte central del texto. De éste se conservan las 5 últimas líneas; superficie bastante deteriorada. Salvo un punto concreto, restitución no ofrece mayores dificultades. Letras regulares de 6,5/7 cm.; puntos redondos; no hay ligaduras.

Sin localización precisa, la pieza procede de Arenzana de Arriba en las proximidades del antiguo Tritium Magallum; fue recuperada por J. Jiménez y J.L. Pérez, de la Asociación Amigos de la Historia Najerillense, a quienes agradecemos la información y las facilidades para el estudio. Autopsia, calco y fotos el 23 de noviembre de 1991 en colaboración con E. Arteaga y M. Pérez Alocén. Se guarda en el Museo Municipal de Nájera. El texto dice (fig. 6 a, b y c):

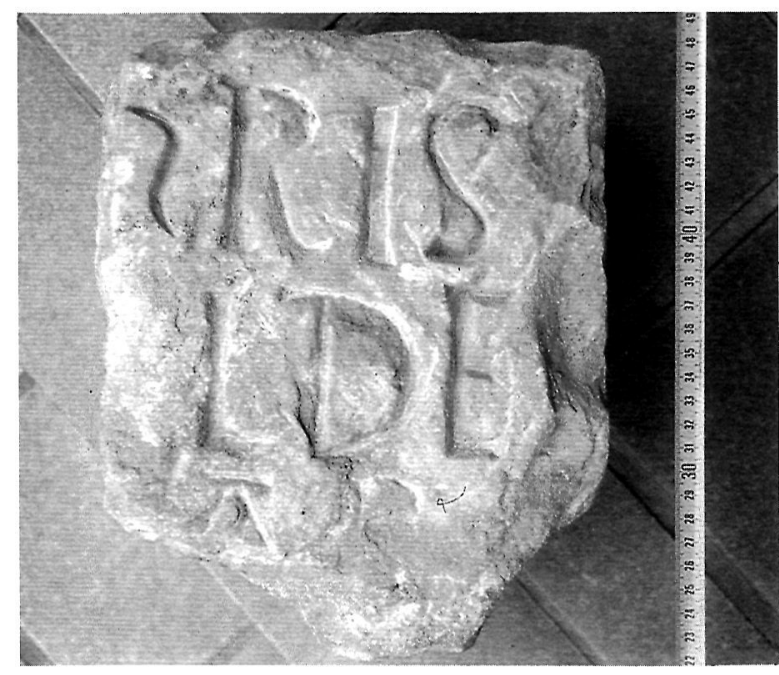

Fig. 5.- Vareia: losa funeraria cristiana 


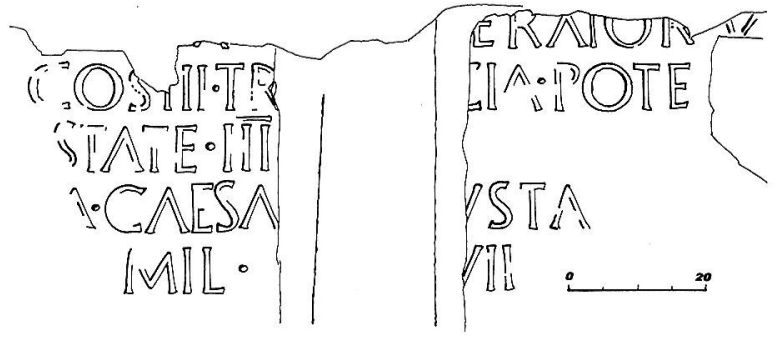

Fig. 6a.- Arenzana de Arriba: texto del milenario de Claudio.

[Tib(erius)·Claudius·Caesar Augustus-Germanicus.pontifex $\cdot \max ($ imus $) \cdot$ imp]erator $\cdot V[?]$ $\operatorname{co}(\mathrm{n}) \mathrm{s}(\mathrm{u}) \cdot \mathrm{III} \cdot \mathrm{tr}[\mathrm{ibuni}] \mathrm{cia}$ pote-

5 state $\cdot$ III. $\cdot[\mathrm{p}($ ater $) \cdot p($ atriae $)]$

a Caesa[raug]usta

mil(lia).[p(assuum) $\cdot$ CXX]VII

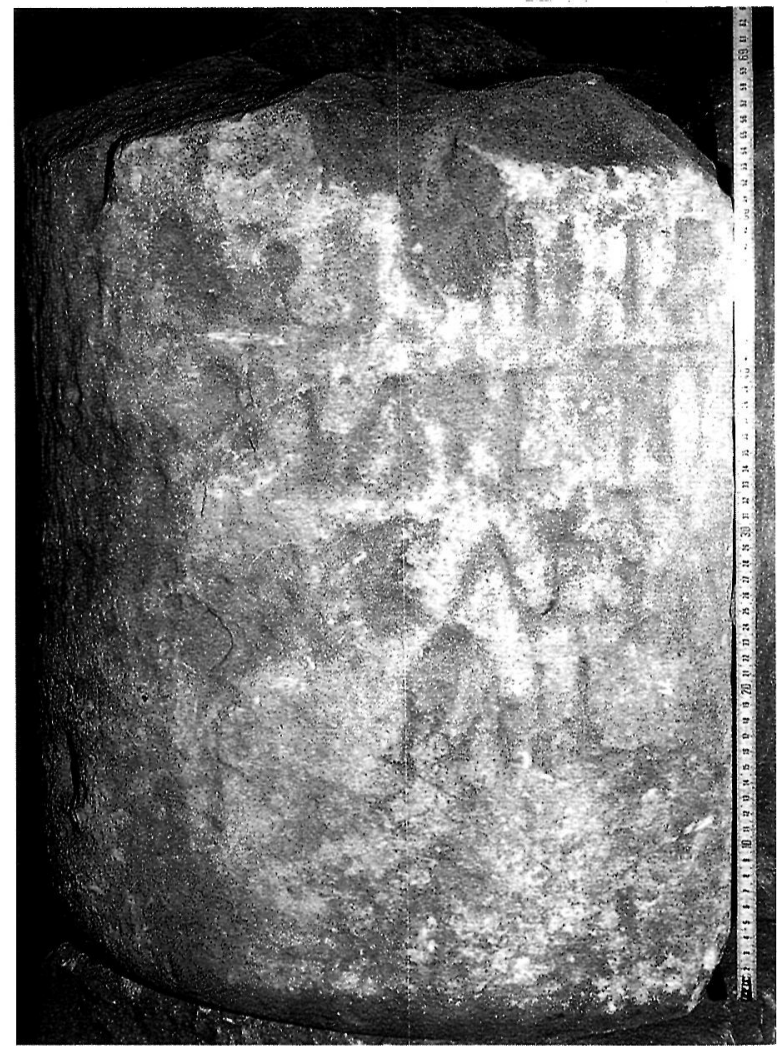

Fig. 6b.- Arenzana de Arriba: miliano de Claudio con la mitad izquierda del texto.

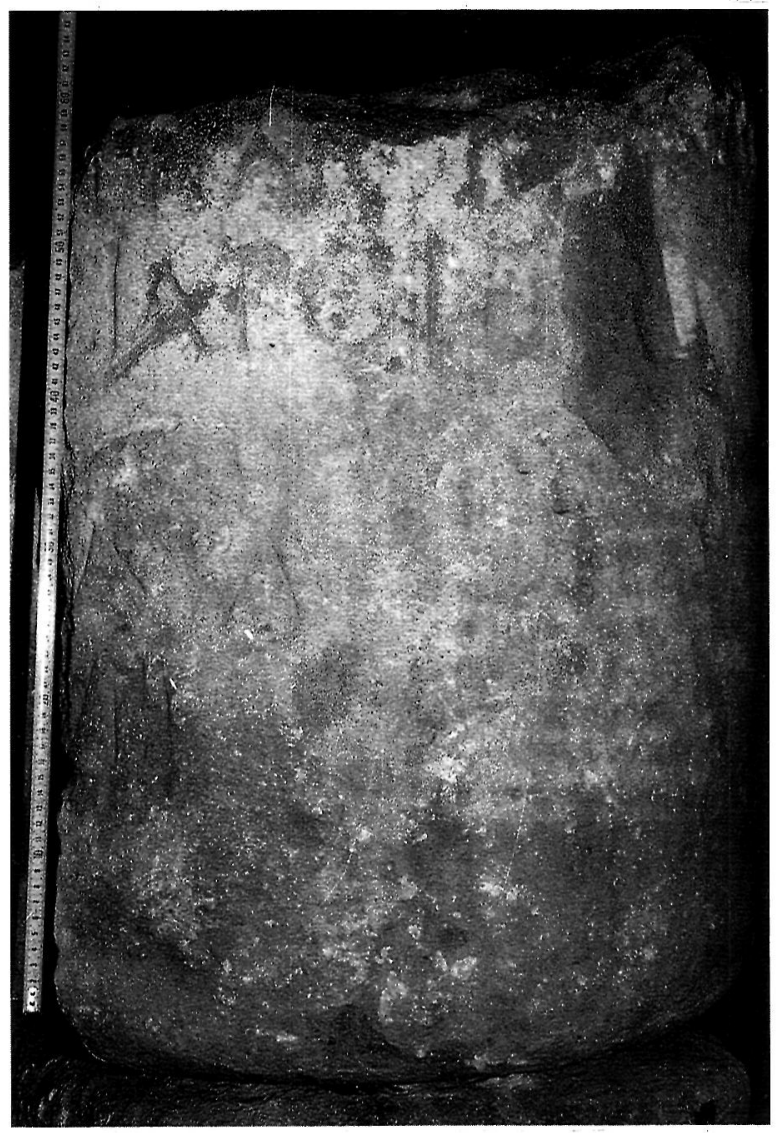

Fig. 6c.- Arenzana de Arriba: miliario de Claudio con la mitad derecha del texto

Es orientativa la reconstrucción de la primera parte del texto. En lín. 3 algunos vestigios inferiores de letras encajarían bien con la secuencia de las letras X-M y con los espacios disponibles. El número de millas se reconstruye como la mayor aproximación posible a las 125 que el Itin. Ant. 392.1394.1 suma desde Caesaraugusta a Tritium Magallum. El miliario de Arenzana se localizaría entre el $3 .^{\circ}$ y el $1 .^{\circ}$ (más probablemente el $2 .^{\circ}$ ) punto miliar antes de que la calzada alcanzara la última ciudad citada; por tanto, la distancia medida entre ambas ciudades bajo Claudio sería de 128/130 millas, de 3 a 5 millas más que las indicadas por el Itin. Antonino. En todo caso, la inscripción prueba que el cómputo de millas se iniciaba en Caesaraugusta, seguramente ya desde que Augusto reparó o construyó esta vía (vid. $\left.\mathrm{n} .^{\circ} 1\right)$.

Por la titulatura imperial conservada, el miliario podría haber sido de Claudio o de Vespasiano. En los años 43 y 71 coinciden cos. III y tr.p. III, así como las aclamaciones imperatorias V-VIII del primero y las VI-VIII del segundo. Por 
argumentos añadidos optamos por atribuir el miliario a Claudio. Hasta el momento no se conocen inscripciones de Vespasiano en Hispania datables antes del 72, pero son bastantes las de Claudio desde inicios del reinado, en particular del año 43/44.

Los trabajos viarios de Vespasiano en Hispania son posteriores al 72, sobre todo en la segunda mitad de su gobierno. Por ejemplo, la inscripción del puente de Chaves (Aquae Flaviae) (CIL II 2477) del 79 d.C., el miliario de S. Joao (Covide) en la vía Bracara-Asturica (II 4814) o el del 79 de cerca de La Carolina (Jaén) (II 5697). En el Ebro no existe miliario alguno de Vespasiano, pero se conocen 4 de Claudio (DUPRÉ 1990,143-154). Por otro lado, el orden de los títulos imperiales en el ejemplar de Arenzana de Arriba no coincide con los miliarios vespasianeos, mientras que es exacto a los de Claudio datados por la tr.p. III entre el 25 de enero del 43 y el 24 de enero del 44; por ejemplo, los del Noroeste: CIL II 4750 y 4771 (Bracara), 4770, 4775 (vía BracaraChaves) y 4875 (Valença do Miño) y en el oriente de la Citerior CIL II 4916 (Lobetum, Albarracín).

El miliario de Arenzana de Arriba prueba reparaciones de la calzada en el área de Tritium Magallum bajo el reinado de Claudio, precisamente cuando empezaba a ponerse en marcha el potente centro alfarero que en la generación siguiente fue el principal punto de fabricación y exportación cerámica de Hispania (MAYET 1984, 59).

\section{Libia (Herramélluri).- Ara votiva.}

Dos fragmentos concordantes de la parte superior de un ara votiva. Piedra arenisca del lugar, muy deteriorada. Conserva la mitad superior del cuerpo central y el lateral izquierdo del superior con sus molduras; apenas se percibe el bulto de un pulvillus, no conserva el focus ni el segundo pulvillus. Pérdida del lateral derecho. Medidas: (35) x (39) x 29 $\mathrm{cm}$. La piedra está cubierta con una capa de cal de tono marmóreo. Campo epigráfico de (12) x $(32) \mathrm{cm}$. conservando sólo las dos primeras líneas de texto, a las que falta 1-2 letras finales. Líneas-guía bien marcadas que igualan la altura de las letras $5 / 5,5 \mathrm{~cm}$. Puntos triangulares.

Hallada en 1989 en el término La Serna en el curso de tareas agrícolas, a las cuales son debidos los destrozos de la piedra. La Serna corresponde al emplazamiento de la antigua Libia de los Berones (Plinio, HN III 2.1; Ptol. II 6.55; Itin.Ant. 394.2; cfr. VILLACAMPA 1980, 56 ss.). La piedra fue rescatada por I. Granado Hijelmo, quien la guarda en su casa de Herramélluri. Inspección, foto y calco en noviembre de 1990. Lectura (fig. 7):

Semp(ronius):M[-2-)

vet(eranus) $\cdot \operatorname{ara}[\mathrm{m}]$

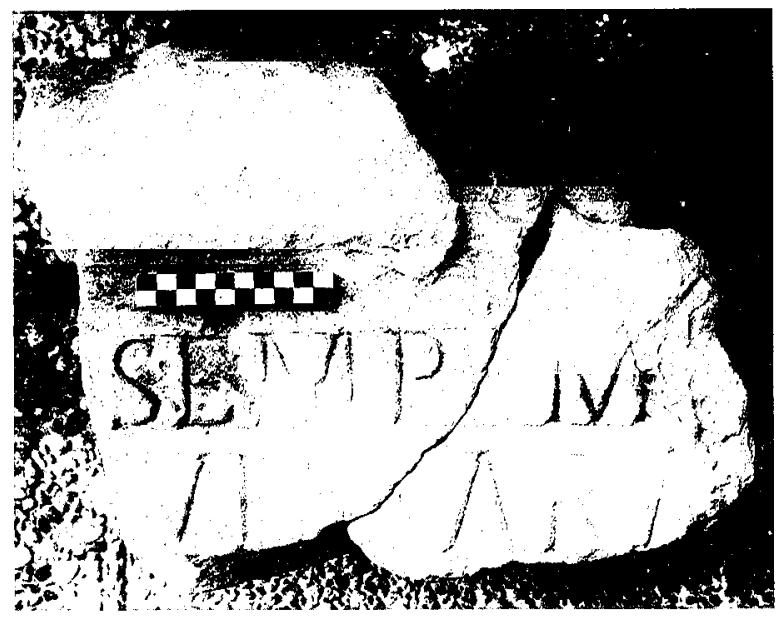

Fig. 7.- Herramélluri (Libia): ara votiva.

Probablemente son dos las líneas que faltan, en las que, además del verbo possuit o similar, constarían el nombre de la deidad y la fórmula votiva final.

Por lo frecuente en la zona, M[at(ernus)] sería una restitución probable del cognomen, pero puede aceptarse cualquier otra solución; por ejemplo, en Libia misma se conoce al uxamense T(itus) Magilius (ESPINOSA 1986, n. ${ }^{\circ} 44$, p. 62 s.). La existencia de líneas-guía en el texto y sus rasgos paleográficos generales permiten aproximar el ara a otras inscripciones libienses, tal vez productos del mismo taller (ESPINOSA 1986, n. $^{\circ} 42,46$ y 48), que se datan en general a lo largo del s. I d.C.; el grupo muestra, además, las M trazadas con los rasgos laterales en vertical. No se menciona la unidad del veterano Sempronius, lo que indicaría que fue auxiliar; unido ello a la ausencia de praenomen en la onomástica, remitiría a una datación anterior a mediados del siglo I d.C.

\section{Camero Nuevo (Montemediano, Nieva). Ara votiva.}

Ara votiva en piedra gneis local, muy deteriorada en ángulos y esquinas: $47 \times 26 \times$ ? cm. No conserva en apariencia los pulvilli laterales. Los remates superior e inferior pudieron haber poseído molduras simples, hoy desaparecidas. Texto en campo de $24 \times 26 \mathrm{~cm}$. Letras de $3,5 / 4 \mathrm{~cm}$. notablemente regulares pese a la tosquedad paleográfica. Puntos sencillos.

Descubierta en 1987 al realizar obras en la vivienda de D. Casimiro Jalón Nájera, sita en la parte alta de la localidad. Se halla en el mismo lugar del hallazgo, empotrada en la pared oriental del edificio a unos $70 \mathrm{~cm}$. del suelo y en posición tumbada; sólo queda visible el frente. Inspección, calco y fotografía en septiembre de 1989. Lectura (fig. 8):

$$
[\cdot] \mathrm{R}[-c a .3-]+\mathrm{N}[\cdot]
$$




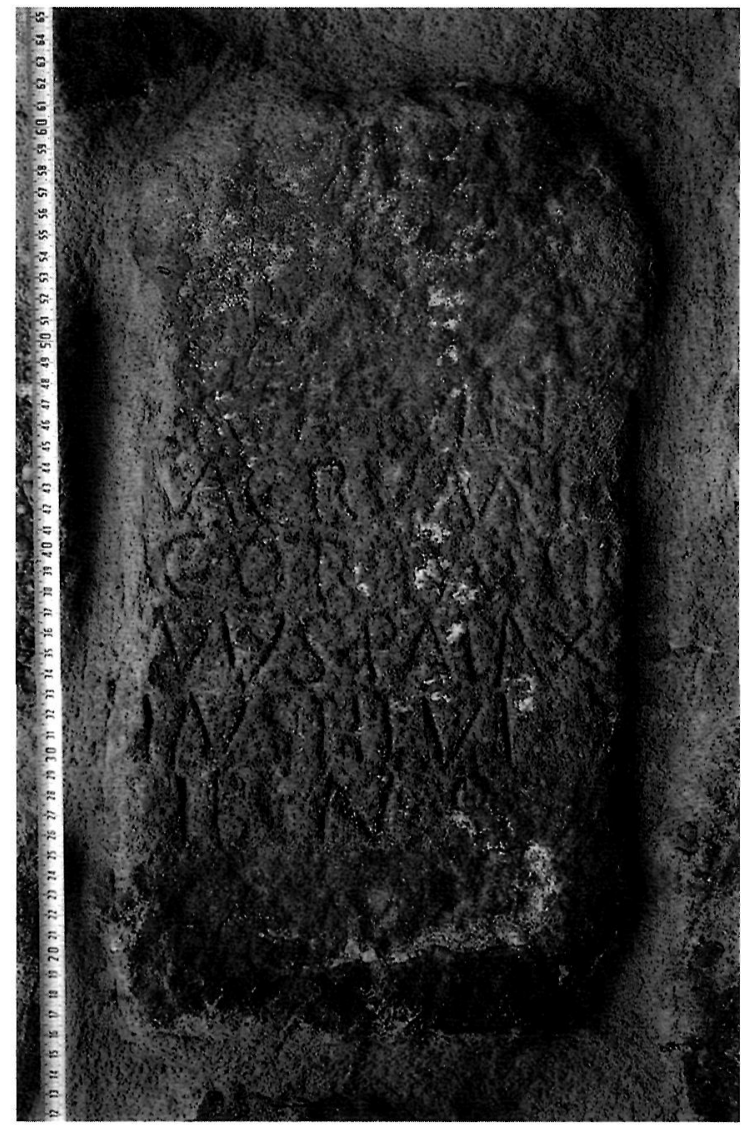

Fig. 8.- Montemediano de Cameros: ara votiva.

sacrum.L(ucius) .

Cor(nelius).Pater-

nus.Palax.

5 institui.

libens

Lín. 1 borrada durante las obras de la vivienda; bastante probable la $\mathrm{R}$ del $2 .^{\circ}$ signo, no tanto la $\mathrm{N}$ del penúltimo. Casi tapadas con cemento la $S$ de lín. 2 y la $L$ de lín. 6.

Bibl.: Boletín Informativo de la Asociación Benéfico-Cultural de Nieva de Cameros 4, Logroño 1988, 60-61 y dibujo, con lectura: JV. . .. . .IN. . ./AC.RVM.L./COR. . .VE/NVS .PAIA./INSTIT.VI/IRMO .O .

Ha sido borrado el nombre de la deidad en lín. 1, cuya restitución es difícil con los elementos conservados. La gens Cornelia aparece con igual abreviatura en la vecina localidad de Ortigosa (Cor(nelia) Sextina: ESPINOSA 1986, N. ${ }^{\circ} 56$ ). Paternus es muy habitual en Cameros y en el área riojana (ESPINOSA 1986, passim), así como en el más amplio horizonte de los distritos centrales de la Península Ibérica (ABASCAL 1984, 253-255).
El segundo cognomen de la inscripción de Montemediano, Palax, es hapax en la onomástica hispana; no se relaciona con el griego Pallas, sino que parece nombre indígena explicable por el radical indoeuropeo pala-, frecuente en numerosos antropónimos, hidrónimos y topónimos de Hispania. Por ejemplo, Palantia. Un Palarus se constata en Barniedo (León) (CIL II 5709), un Paligo en Amallobriga (Hisp. Epigraphica 1, 1989, n. ${ }^{\circ}$ 645) y una Palacia en Adeganha (Torre de Moncorvo, Braganca) (NUNES 1984, n. ${ }^{\circ}$ 42 , p. 3-6 = $A E 1985,576)$. Una pepita de oro en Hispania recibe el específico y curioso nombre de pala en Estr. 3.2.8. Palaga, palacurna, balux en Plin. HN 33.77 y paludis en Marcial, Epigr. 12.57.9. Balluca en Veg. Mulom. I.20.3 y en Cod. Theod. X.19.3-4. La raíz indoeuropea del vocablo en HOLDER, col. 922 s., que aparece en diversos topónimos e hidrónimos hispanos (MENÉNDEZ PIDAL, 1952, 166). En la onomástica hispana, (ALBERTOS 1966, 176).

La fórmula final de la inscripción de Libia es peculiar. No se puede asegurar, tampoco excluir, que el ara procede de la officina lapidaria conocida en Camero Nuevo (ESPINOSA 1989, 403415). Los tria nomina del dedicante permiten datar la inscripción de modo amplio en el siglo II, antes de la pérdida del praenomen al final de esa centuria y durante la siguiente.

\section{EPIGRAFÍA SOBRE CERÁMICA: EL CALAGURRITANO G. VALERIUS VERDULLUS.}

Durante los últimos años la investigación ha identificado en la cuenca del Ebro y en el oriente de la Citerior un peculiar grupo de vasos de paredes finas ejecutados a molde y con decoraciones figuradas e inscripciones. Unas 40 piezas forman el inventario actualmente conocido, que atribuimos con seguridad a $G$. Valerius Verdullus. La unidad del grupo se evidencia en la técnica y calidad cerámicas, en los recursos decorativos y en los esquemas compositivos. La mayor parte de las piezas portan inscripciones con caracteres paleográficos muy similares entre sí; puede defenderse la unidad de taller y la virtual coetaneidad de todos los ejemplares. Aquí damos a conocer 5 piezas de Vareia (Varea, Logroño) y 4 de la villa romana de Quilinta (Viana, Navarra), alguna de las cuales, como veremos, resulta decisiva para desvelar la identidad y la origo del officinator Verdullus .

Quilinta se localiza a unos $4 \mathrm{~km}$. al norte de Varea, en la margen izquierda del Ebro; la villa nació históricamente hacia principios de Claudio, sustituyendo en el ordenamiento del territorio a la berona Vareia (La Custodia), junto a cuyo solar emergió; la villa surge asociada al cierre del campamento de la legión IV Macedónica, emplazado al sur del Ebro, y la conversión de éste en la civil y romana Vareia, actual Varea junto a Logroño (ESPINOSA 1990, 6 ss.). 


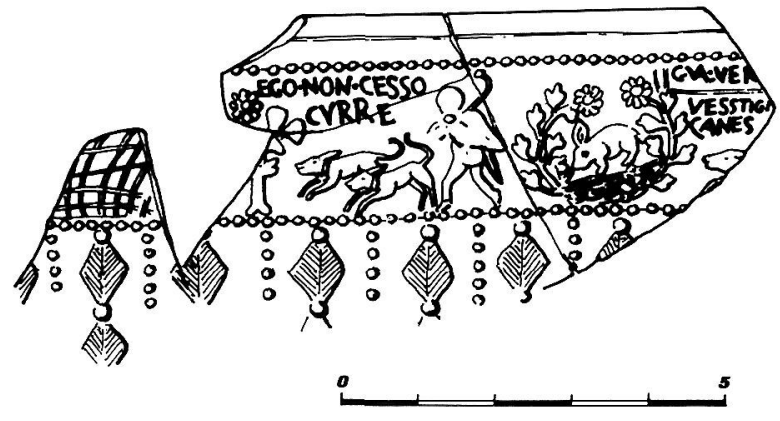

Fig. 9.- Vareia: ornamentación y epígrafe del vaso n. ${ }^{\circ}$ de Verdullus.

\section{a) Las inscripciones cerámicas vareyenses.}

\section{Vareia (Varea, Logroño) (fig. 9).}

Vaso de paredes finas forma 37 (MAYET 1975, 73, láms. 38 ss.). Pasta arenosa con superficies pigmentadas en tonos que oscilan del rojo al marrón oscuro y al granate. Doble línea de perlitas delimitan arriba un friso con escena de caza del conejo o liebre; de izquierda a derecha vemos un entramado que podría representar una red o valla; luego motivos vegetales convencionales, flores y tal vez un árbol. La escena principal está formada por dos perros a la carrera seguidos por un hombre corriendo; la figura humana está deteriorada, pero parece vestir ropas ajustadas, sobre los hombros una especie de clámide corta (alicula), en la mano izquierda probablemente una honda y en la derecha la vara (pedum) con final curvo apoyando en el hombro, habitual en la caza de la liebre. Tras el cazador hay un nicho de hierbas, ramas y flores en el que se oculta un conejo o liebre; seguían otros perros a la carrera. El naturalismo en la ejecución de las figuras humanas y animales contrasta con el convencionalismo de los elementos vegetales y del montaje del escenario campestre. El casquete inferior del vaso está decorado con alternancia de columnas de hojas con perfil rómbico y líneas de perlas.

La pieza apareció en la campaña de excavación de 1990, junto a las dos siguientes, en el nivel VI (profundo) de un sondeo realizado en regio IV, insula 10, habitación 20; el estrato era un embolsamiento de cenizas que reposaba directamente sobre el suelo originario y contenía también cerámicas de cáscara de huevo, itálicas y de tradición indígena; referencia de campaña: V90 sector I hab. E nivel VI talla 1 (sondeo); el punto de hallazgo, en MARTÍNEZ CLEMENTE y CASTILLO 1995. Se trata de un conjunto arqueológico cuya cronología va desde finales de Tiberio hasta Nerón.

El vaso conserva dos inscripciones, cada una colocada sobre una escena de perros; dos líneas tiene la primera y tres la segunda. Letras capitales de ductus irregular, 2 a $3 \mathrm{~mm}$. de

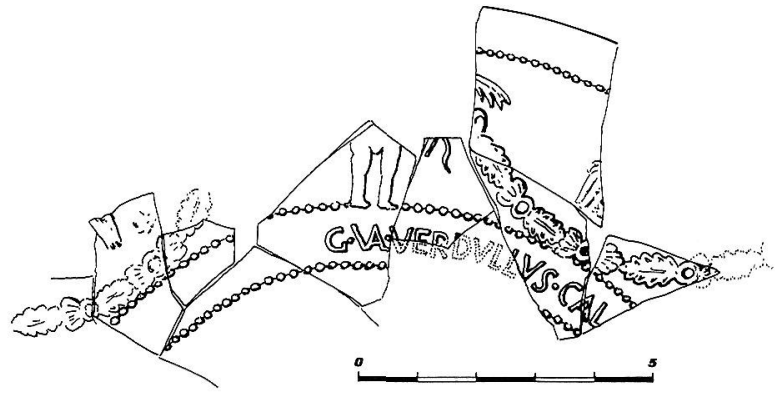

Fig. 10.- Vareia: vaso n. 2 que indica la origo calagurritana de Verdullus.

altura con relieve poco marcado; puntos redondos y ligadura VAL. Se guarda en el Museo de La Rioja. Lectura:
A: Ego-non cesso curre(re)
B: G(aius)·Vâl(erius)·Ver[dullus] vesstiga $[\mathrm{t}]$ canes

En B) el nombre va dentro de una cartela; geminación de $\mathrm{S}$ en lín. 2.a. Resolvemos en nominativo la onomástica por paralelo con otros vasos; menos probable en vocativo y verbo en imperativo .

\section{Vareia (Varea, Logroño) (fig. 10).}

Vaso de igual forma que n. ${ }^{\circ}$. Pared tipo cáscara de huevo, con pasta color ocre y superficie interior arenosa; conservación defectuosa. Doble línea de perlas delimitan un friso con decoración de guirnaldas; en la unión de éstas parece interponerse una figura humana y otros motivos vegetales indeterminados; sobre la parte cóncava de las mismas, tal vez bucráneo.

Hallazgo y cronología como n. ${ }^{\circ}$ anterior. La inscripción se halla a la altura de la carena y dispuesta en una banda entre líneas de perlas. Mal conservada, pero lectura asegurada. Letras de $5 \mathrm{~mm}$. y ductus regular; puntos redondos y ligadura VAL. Se guarda en el Museo de La Rioja. Lectura:

\section{G(aius)·Vâl(erius)·Ver[dul]lus·Cal[agurritanus]}

Es el primer vaso conocido en el que Verdullus explicita su origo; desarrollado de modo convencional el gentilicio, pues en origen podía ir en abreviatura o reflejar el nombre de Calagurris en genitivo o ablativo.

3. Vareia (Varea, Logroño) (fig. 11).

Hallazgo y forma como $n .^{\circ} 1$. Vaso con engobe rojizo y 


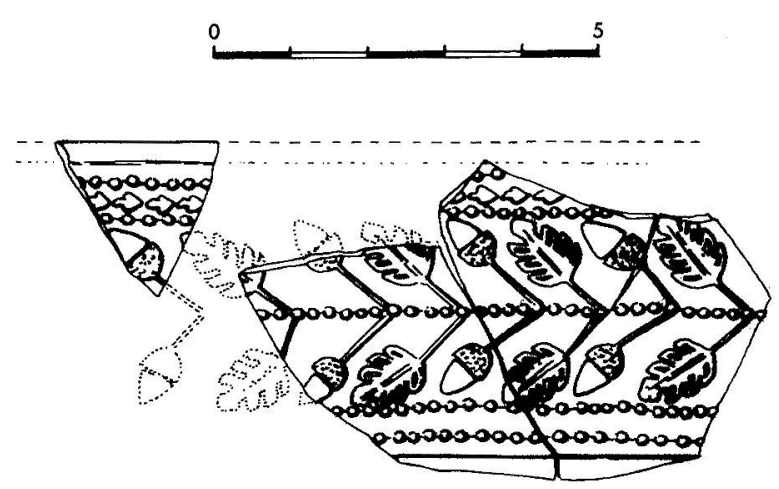

Fig. 11.- Vareia: vaso n. $^{\circ} 3$ de Verdullus con inscripción perdida.

marrón al exterior y al interior casi negro con arenillas. Frisos delimitados por líneas de perlitas. Arriba uno de pequeñas hojas y debajo el principal, donde a cada lado de un eje de simetría se alternan hojas de encina y bellotas. Junto a la carena queda un pequeño resto de banda delimitada por doble línea de perlas; seguramente esta banda portaba inscripción en la parte perdida. Se guarda en el Museo de La Rioja.

\section{Vareia (Varea, Logroño) (fig. 12).}

Hallazgo durante las excavaciones de 1990 en regio IV, insula 5 y hab. 4 (Nivel II y talla 1), a unos $80 \mathrm{~m}$. de distancia de las anteriores y en un ambiente cronológico similar a ellas, sigla de campaña: V90, sector II, área 4 (para localización, vid. MARTÍNEZ CLEMENTE Y CASTILLO 1995). En la parte inferior de un cuenco decorado en sentido radial alternativamente con columnas de hojas rómbicas y líneas de perlas (igual a . $^{\circ} 1$ ). Pigmento marrón oscuro y negro en ambas superficies, con arenillas adheridas en la interior. Junto a la carena, una banda delimitada por doble línea de perlas portaba la inscripción, de la que sólo se conserva la parte inferior de una F ó P. Se guarda en el Museo de La Rioja.

\section{Vareia (Varea, Logroño).}

Se tiene noticia verbal de un fragmento de Varea con figura humana perteneciente a la producción de Verdullus (excavaciones de S. Andrés, MÍNGUEZ 1989, 186).

\section{Villa romana de Quilinta (Viana) (fig. 13.1).}

Hallazgo superficial. Fragmento de borde, $3 \mathrm{~cm}$. bajo el labio una línea de perlas da lugar a un motivo floral con inscripción (contexto arqueológico de ésta y de las tres siguientes piezas, LABEAGA 1995):

$$
\text { [---? G(aius)·Vâl(erius)]·Ver[dullus---?] }
$$
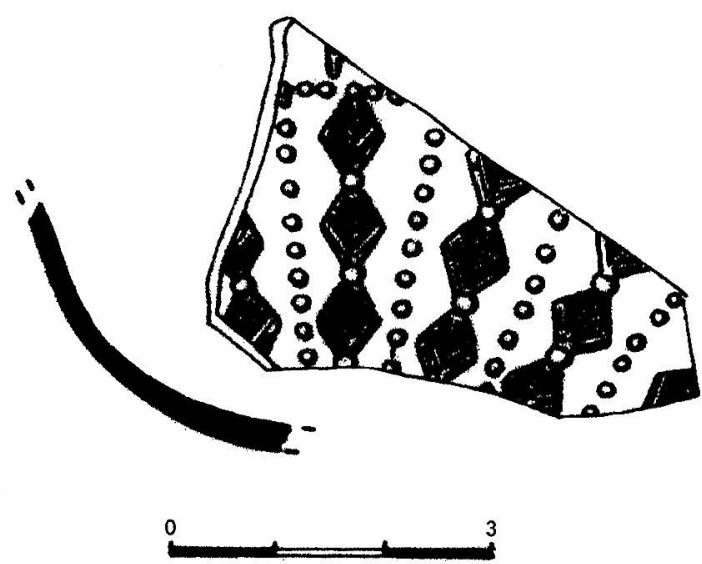

Fig. 12.- Vareia: vaso n. ${ }^{\circ} 4$ de Verdullus con restos de inscripción.

\section{Villa de Quilinta (Viana) (fig. 13.2).}

Hallazgo superficial; borde con líneas de perlas y debajo bellotas y hojas de encina conserva la cabeza de una figura humana y en torno a ella la inscripción en doble línea:

$$
\begin{aligned}
& \text { G(aius)·Vâl(erius)·Verdullu[s] } \\
& \text { pingît }
\end{aligned}
$$

8. Villa de Quilinta (Viana) (fig. 13.3).

Hallazgo superficial: fragm. de borde; perlitas en línea horizontal y junto a ella restos motivo indeterminado y parte de una inscripción en doble línea:

$$
\begin{aligned}
& {[---] \cdot \text { Blastus }} \\
& {[---v] \text { eneti }}
\end{aligned}
$$

Blastus es cognomen griego con paralelos en Hispania (CIL II 1149: Itálica, 4970.88: Tarraco); Blastinus: II 4018). El texto de la segunda línea parece aludir a una de las factiones (la azul) del circo, por lo que podemos presumir que portaría decoración de tema circense.

\section{Villa de Quilinta (Viana) (fig. 13.4).}

Fragmento de $3,2 \mathrm{~cm}$. y hallazgo superficial; junto a la carena doble línea de perlitas y encima una persona (apenas visible) ordeñando una cabra. El vaso no conserva la inscripción que seguramente poseería en origen.

\section{b) Centro de producción y cronología.}

Calahorra y su entorno se han constituido como el principal centro de hallazgos de Verdullus con numerosísimas piezas; tres proceden del enclave calagurritano mismo y el resto, 

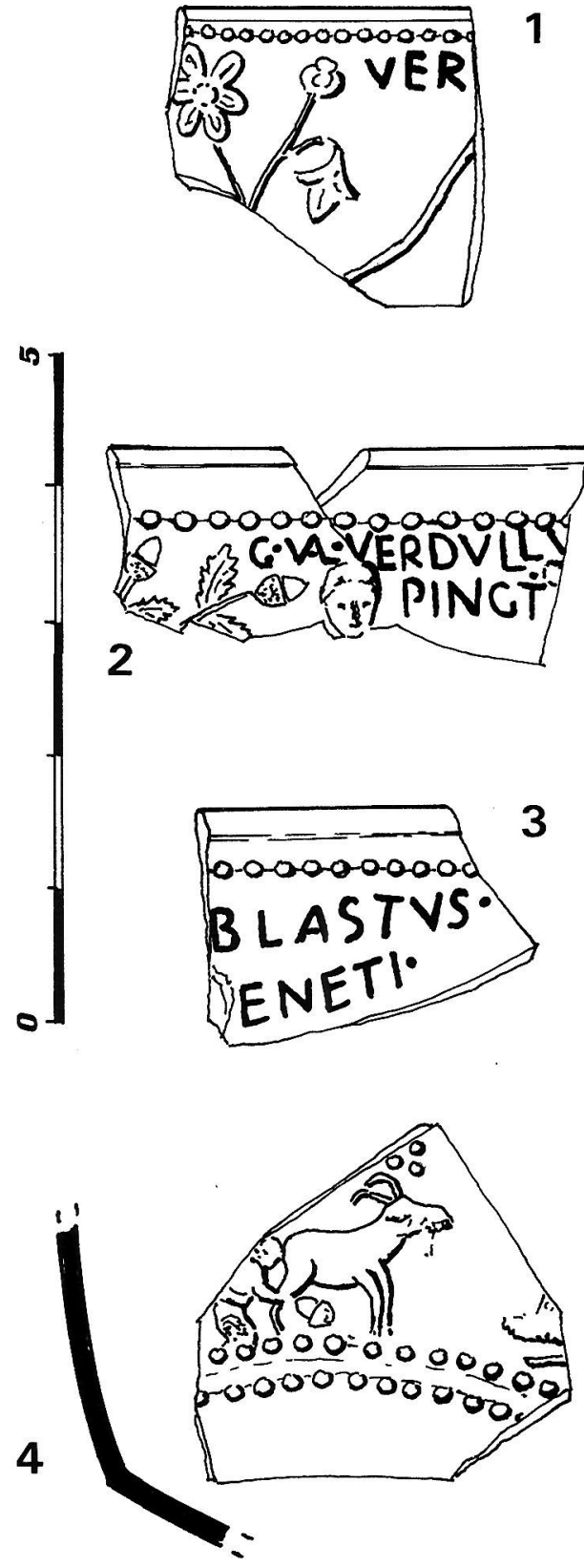

Fig. 13.- Quilinta (Viana, Navarra): hallazgos cerám Verdullus.

lo que resulta especialmente relevante, se han localizado en el alfar de La Maja (Pradejón-Calahorra) (AGUINAGA 1984, 201-205 y fig.; ESPINOSA 1986, ID 5 y 6, p. 122; MÍNGUEZ 1989, 182, fig. 2; Miscelánea: Arqueología de Calahorra, Logroño 1991, p. 258-262; GONZÁLEZ BLANCO y AMANTE 1992, 47 ss., a quienes agradecemos la información manuscrita anticipada). Sin duda han sido decisivos los numerosos hallazgos recuperados en el citado alfar durante las campañas de excavación de 1991 a 1994 dirigidas por el Prof. Antonino González Blanco. Hoy no cabe la menor duda que Verdullus produjo aquí el grupo de cerámicas a las que nos referimos (GONZÁLEZ BLANCO et alii 1989 y 1991).

Un interesante vaso con escena de carrera circense ha aparecido en Partelapeña (El Redal), en el contexto de una villa altoimperial sita al pie del famoso yacimiento de la Edad del Hierro (MÍNGUEZ et alii 1989, 184, n. ${ }^{\circ}$ 6, fig. 2). Una pieza de Arcobriga (Monreal de Ariza) recoge una mención a las fiestas Saturnales (MÍNGUEZ 1989, 184, N. 11, fig. 3). Celsa ha dado hasta ahora 4 fragmentos de cerámica a molde de Verdullus, de los cuales uno recuerda de nuevo las Saturnales: [-Saturna]lia municipio.Calag[urritano ---] BELTRÁN 1977, 145-152; BELTRÁN 1984, 129-138; MÍNGUEZ 1989, 184, n. ${ }^{\circ}$ 7-10, fig. 3). Tenemos constancia de un nuevo hallazgo en Tarragona (claustro de la catedral) (RÜGER 1968, 246, lám. 71,16; MÍNGUEZ 1989, 184-186, n. ${ }^{\circ}$ 11) y otro en Baetulo (PUERTA 1989, 54-56, fig. 48), si bien no es segura la adscripción de este último a Verdullus. A buen seguro que Verdullus fabricó otras variantes de paredes finas y otros tipos de barros. De hecho, también vendía vasos de terra sigillata Hispanica, que se hacía modelar en la zona de Tritium Magallum (GARABITO y SOLOVERA 1992, 13, n. ${ }^{\circ}$ 4). Su ámbito comercial parece extenderse por el Ebro y por la costa nororiental de provincia Citerior (fig. 14).

El nombre del officinator, en general bajo la fórmula $G$. VAL. VERDULLUS, se reitera al menos en docenas de ocasiones. El nomen se abrevia VAL (las tres letras ligadas) en todos los casos menos uno. Sin lugar a dudas, el personaje no es un simple figlinarius implicado personalmente en la manipulación del barro; posee el derecho ciudadano y pertenece a la élite del municipio Calagurris Iulia Nassica; ilustres predecesores suyos serían los 4 Valerii que alcanzaron la edilidad y el duunvirado en época de Augusto y de Tiberio (ESPINOSA 1984, 76 y 96 ss.). Miembro de las élites urbanas del Ebro, imaginamos

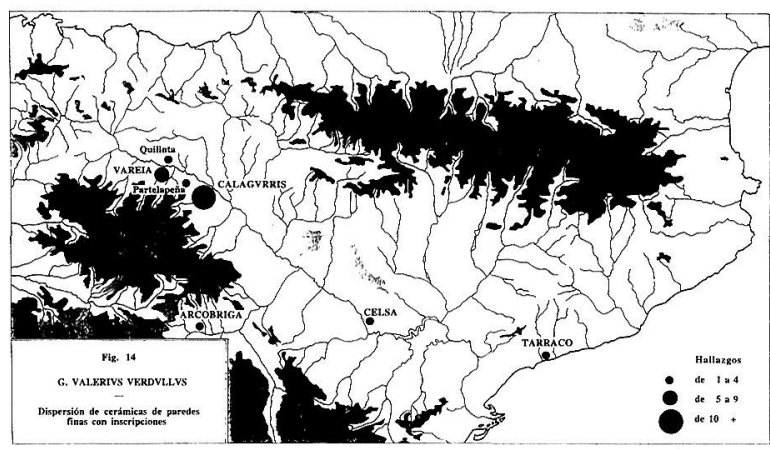

Fig. 14.- 
a Verdullus como negotiator o mercator rei cretariae, mayorista por tanto, y de ahí pueda explicarse que produzca simultáneamente vasijas en alfares de varias ciudades. Son otras personas, los figlinarii, quienes producen para él bajo cualquier fórmula contractual o de dependencia en los alfares de La Maja (Pradejón-Calahorra) y de Cauce Molinar (Arenzana de Arriba), este último en territorium de Tritium Magallum. Por ello parece que debe tomarse en sentido figurado, más que propio, la expresión pingit de los vasos de Varei $\left(n .^{\circ} 7\right)$, de La Maja (Calahorra) y de Arcóbrig (Monreal de Ariza).

El hallazgo del crucero de la catedral de Tarragona aparece en el nivel $\mathrm{G}$, que se data en época neroniana y principios de la flavia (RÜGER 1968, 239). Por el momento desconocemos fechas absolutas en el alfar de La Maja (Pradejón, Calahorra). Como dijimos, los hallazgos de Vareia (n. $\left.{ }^{\circ} 1-4\right)$ aparecen en niveles datables entre finales de Tiberio y Nerón, al tiempo que la villa de Quilinta surgió en el ager Vareiensis no antes de comienzos del reinado de Claudio; no existe, pues, contradicción entre los diversos elementos cronológicos y de ahí que el conjunto que estudiamos pueda datarse con mayor precisión en el tercer cuarto del s. I d.C., desde final del reinado de Claudio (aprox. 50/54) a principos del de Vespasiano (70/75).

\section{BIBLIOGRAFÍA}

ALBERTOS, M.L., 1966: La onomástica personal primitiva de Hispania tarraconense y bética. Salamanca.

ALFÖLDY, G., 1975: Römische Inschriften von Tarraco. Berlín, n. ${ }^{\circ} 356$.

- 1984: Drei städtische Eliten im römichen Hispanien, Gerión 2, 217.

ANDRÉS, S. y TIRADO, J.A., 1991: Varea 1979-1988: epigrafía y numismática, Berceo 120, $10 \mathrm{~s}$.

BELTRÁN, F., 1980: Epigrafía romana de Sagunto. Valencia, n. ${ }^{\circ} 47,48,63$, 214

BELTRÁN, M., 1969/70: Notas arqueológicas sobre Gallur y la comarca de las Cinco Villas de Aragón, Caesaraugusta 33-34, 99-100.

- 1977: Novedades sobre cerámica romana de Celsa, Estudios III. Zaragoza, 145-152.

- 1984: Ludus Calagurritanus: relaciones entre el municipium Calagurris lulia y la Colonia Victrix lulia Celsa, Calahorra, bimilenario de su fundación. Madrid 129-138.

CASTILLO, C., 1981: Un nuevo documento de la «leg. IV Macedónica» en Hispania, I Reun. Gallega de Estudios Clásicos, Santiago de Compostela, 134-140.

CASTILLO et alii., 1981: Inscripciones romanas del Museo de Navarra. Pamplona, $n .{ }^{\circ} 1$ y 2.

DUPRE, N., 1990: Informatique et étude du reseau routier romain. Les milliaires de la region de l'Ebre, Simposio La red viaria en la Hispania romana. Zaragoza, 143-154

ESPINOSA, U., 1984: Calagurris Iulia. Logroño,

- 1986: Epigrafía romana de La Rioja. Logroño.
- 1989: Una officina lapidaria en la comarca de Camero Nuevo, anexos Gerión Il (Homen. a Santiago Montero Díaz), Madrid, 403-4I5.

- 1990: Vareia: enclave romano en el valle del Ebro. Logroño.

- 1995: Vareia: arquitectura funeraria, en Hist. de la Ciudad de Logrono. Logroño (prensa).

FATAS, G., 1975: Nota sobre Caesaraugusta y la tribu Aniense Caesaraugusta $39-40,135$ ss.

FATAS, G. y MARTÍN, M., 1977: Epigr. romana de Zaragoza y su provincia. Zaragoza, $n^{\circ} 69$ y 71 .

GARABITO, T. y SOLOVERA, E., 1992: Las firmas de los fabricantes de moldes en Tritium Magallum, Estrato 4, 9-16.

GONZÁLEZ BLANCO, A., et alii, 1989: El alfar romano de La Maja: Pradejón-Calahorra, Estrato 1, 54.

- 1991: El alfar de La Maja (Calahorra, La Rioja) y las perspectivas arqueológicas de las nuevas tecnologías, Estrato 3, 52.

GONZÁLEZ BLANCO, A. y AMANTE, M., 1992: El alfar de La Maja (Pradejón-Calahorra, La Rioja) y su importancia para la epigrafía romana y calagurritana, Estrato 4, 47-54. (= Congreso de Epigrafia Peninsular, Zaragoza, octubre 1992)

HOLDER, A., 1904: Alt-Celtischer Sprachschatz II. Leipzig, $922 \mathrm{s.}$

LABEAGA, J.C., 1995: Quilinta, en Historia de la Ciudad de Logroño. Logroño (prensa).

LE ROUX, P., 1982: L'armée romaine et l'organisation des provinces ibér. d'Auguste a l'invasion de 409. París, $84 \mathrm{~s}$.

- 1992: L’Armée romaine dans la Péninsule lbérique sous l'Empire: Bilan pour une décennie, REA 94, 231-257.

MARTÍNEZ CLEMENTE, J. y CASTILLO, M.a J., 1995: Vareia: Investigación y fuentes arqueológicas, Historia de la Ciudad de Logrof̂̃o, cap. 9: La investigación y las fuentes. Logroño (prensa).

MAYET, F., 1975: Les céramiques a parris fines dans la Péninsule Ibérique. París, p. 73, láms. 38 ss.

- 1984: Les céramiques sigillées hispaniques. París, 59 ss.

MENÉNDEZ PIDAL, R., 1952: Toponimia prerrománica hispana. Madrid, 166.

MÍNGUEZ, J.A., 1989: La producción de paredes finas con decoración a molde del ceramista $G$. Valerius Verdullus y su difusión por el valle del Ebro, S.F.E.C.A.G., Actes du Congress de Lezoux, p. 186.

MÍNGUEZ, J.A. et alii, 1989: La cerámica de paredes finas procedente del yacimiento de Partelapeña (El Redal, La Rioja), Berceo 116-17, 58 ss. lám. II.

NUNES, A.J., 1984: Inscricao funeraria de Adeganha (Moncorvo), Fich. Epigraphico 10, n. $^{\circ} 42$, p. 3-6 (= $\left.\mathrm{AE} 1985,576\right)$.

PASCUAL, J.M. y ESPINOSA, U., 1982: Aportación al estudio de las vías romanas en el Ebro medio; desembocaduras del Iregua y del Leza, Berceo 101, 70 ss. y figs. 2-3.

PUERTA, C., 1989: Baetulo, cerámica de parets fines. Badalona, 54-56, fig. 48.

ROLDÁN, J.M., 1975: Itineraria Hispana. Madrid.

RÜGER, Chr.B., 1968: Römische Keramik aus dem Kreuzgang der Kathedrale von Tarragona, M.M. 9, 246, lám. 71,16.

SYME, R., 1960: Pliny's less successful friends, Historia 9, 365 ss. (= Roman Papers II, 1979, 480 ss.).

VILLACAMPA, M.A., 1980: Los Berones según las fuentes escritas. Logroño WIEGELS, R., 1985: Die Tribusinschriften des röm. Hispaniens. Berlín. 